\title{
Seasonal Variations of Mesospheric Gravity Waves Observed with an Airglow All-sky Camera at Mt. Bohyun, Korea $\left(36^{\circ} \mathrm{N}\right)$
}

\author{
Yong Ha Kim ${ }^{1 \dagger}$, Changsup Lee ${ }^{1}$, Jong-Kyun Chung ${ }^{2}$, Jeong-Han Kim ${ }^{3}$, and Hye-Yeong Chun ${ }^{4}$ \\ ${ }^{1}$ Department of Astronomy and Space Science, Chungnam National University, Daejeon 305-764, Korea \\ ${ }^{2}$ Korea Astronomy and Space Science Institute, Daejeon 305-348, Korea \\ ${ }^{3}$ Korea Polar Research Institute, Incheon 406-840, Korea \\ ${ }^{4}$ Department of Meteorology, Yonsei University, Seoul 120-749, Korea
}

We have carried out all-sky imaging of $\mathrm{OH}$ Meinel, $\mathrm{O}_{2}$ atmospheric and OI $557.7 \mathrm{~nm}$ airglow layers in the period from July of 2001 through September of 2005 at Mt. Bohyun, Korea $\left(36.2^{\circ} \mathrm{N}, 128.9^{\circ} \mathrm{E}\right.$, Alt $\left.=1,124 \mathrm{~m}\right)$. We analyzed the images observed during a total of 153 clear moonless nights and found 97 events of band-type waves. The characteristics of the observed waves (wavelengths, periods, and phase speeds) are consistent with internal gravity waves. The wave occurrence shows an approximately semi-annual variation, with maxima near solstices and minima near equinoxes, which is consistent with other studies of airglow wave observations, but not with those of mesospheric radar/lidar observations. The observed waves tended to propagate westward during fall and winter, and eastward during spring and summer. Our ray tracing study of the observed waves shows that majority of the observed waves seemed to originate from mesospheric altitudes. The preferential directions and the apparent source altitudes can be explained if the observed waves are secondary waves generated from primary waves that have been selected by the filtering process and break up at the mesospheric altitudes.

Keywords: gravity wave, airglow, mesosphere, all-sky observation

\section{INTRODUCTION}

Atmospheric gravity waves are known to be a significant source of momentum and energy to the mesosphere and lower thermosphere, where they become unstable and dissipate (e.g., Lindzen 1981, Fritts \& Alexander 2003, reference therein). Wave phenomena near the mesopause are reflected in the airglow layers of $\mathrm{OH}$ Meinel, OI $557.7 \mathrm{~nm}, \mathrm{O}_{2}$ atmospheric band and $\mathrm{Na} 589.7 \mathrm{~nm}$, and have been observed with optical devices such as scanning photometers, spectral airglow temperature imagers (SATI) and all-sky imagers. Numerous studies have been carried out using all-sky imagers, such as Taylor et al. (1987), Hecht et al. (1994) and Smith et al. (2000), among others. All-sky imaging of the airglow provides direct images of waves, from which their wavelengths, phase speed, propagation directions and other parameters can be determined. Various types of quasi-monochromatic waves were detected in the images that cover the $180^{\circ}$ field of view (FOV) or about a $450 \mathrm{~km}$ region radially at a $90 \mathrm{~km}$ airglow layer.

Among the different types of wave features reported with all-sky imaging of mesospheric airglow (Taylor \& Hapgood, 1990 and reference therein), the band-type waves usually span horizon-to-horizon in all-sky images. Their horizontal wavelengths are generally greater than $\sim 10 \mathrm{~km}$. The band-type waves are believed to be due to short-period $(<1$ hour) internal gravity waves that propa- (c) This is an Open Access article distributed under the terms of the Creative Commons Attribution Non-Commercial License (http://creativecommons.org/licenses/by-nc/3.0/) which permits unrestricted non-commercial use, distribution, and reproduction in any medium, provided the original work is properly cited.
Received Jul 23, 2010 Revised Aug 10, 2010 Accepted Aug 13, 2010 ${ }^{\dagger}$ Corresponding Author

E-mail: yhkim@cnu.ac.kr

Tel: +82-42-821-5467 Fax: +82-42-821-8891 
gate freely, horizontally and vertically, or that have been ducted by vertical wind or temperature shears in the mesosphere (Taylor et al. 1993, Isler et al. 1997). The bandtype waves may thus reflect regional characteristics more efficiently than other in situ wave phenomena.

Although the main characteristics of the band-type waves seem to be understood, their sources and variation by season and geographic location have not been addressed well. Seasonal variations of gravity wave activity near the mesopause have been studied with SATI, MF radars, and lidars (Gavrilov et al. 2002, 2003, Yang et al. 2006), but not with all-sky imagers. All-sky images are often tempered with clouds and local light conditions, making it difficult to determine wave occurrence properly. In order to overcome this difficulty, in this study we apply coherent selection criteria of wave detection and clear night conditions to more than 640 hrs worth of allsky airglow images. The images were obtained with the $\mathrm{OH}$ Meinel band, OI 557.7, and $\mathrm{O}_{2}$ atmospheric band airglow filters at Mt. Bohyun $\left(36.16^{\circ} \mathrm{N}, 128.98^{\circ} \mathrm{E}\right.$, Elevation $=1,124 \mathrm{~m}$ ) from July 2001 through September 2005 .

\section{THE ALL-SKY AIRGLOW CAMERA SYSTEM}

The all-sky camera system consists of a fish eye lens with $180^{\circ}$ FOV (Mamiya RB 37 mm / F4.5), telecentric optics for 4 inch diameter narrow-band filters, a five-position filter wheel, re-imaging optics, and a liquid-cooled back-illuminated $1024 \times 1024$ charged coupled device (CCD). The pixel size of the CCD chip is $24 \mu \mathrm{m}$, which corresponds to $0.3 \mathrm{~km}$ toward zenith at $90 \mathrm{~km}$. Similar systems have been used for previous airglow imaging studies, such as Taylor et al. (1998) and Garcia (1999), among others. During the first year of observation in 2001-2002, three narrow-band filters of $630 \mathrm{~nm}, 589.7 \mathrm{~nm}$ and 572.9 $\mathrm{nm}$ were used for OI airglow emissions, Na airglow emissions, and a background, respectively, and a wide-band filter of 720-910 nm notched at $865 \mathrm{~nm}$ was used for $\mathrm{OH}$ airglow emissions. In 2002, a narrow band filter of 557.7 $\mathrm{nm}$ for OI airglow was installed in place of the Na filter, which did not produce quality images at our observation site. In 2003, a $10 \mathrm{~nm}$ bandwidth filter of $865.7 \mathrm{~nm}$ for the $\mathrm{O}_{2}$ atmospheric band was added in the system. When observation resumed in October 2003, the $\mathrm{OH}$ filter was replaced with a new $\mathrm{OH}$ filter with a central wavelength at $770 \mathrm{~nm}$ and a bandwidth of $100 \mathrm{~nm}$.

All-sky images with the $\mathrm{OH}$ filter were taken with $2 \times 2$ binning of the CCD, and images with other narrow band filters were obtained with $4 \times 4$ binning to increase signal to noise ratios. All images were digitized to a 16-bit resolution. During the normal observation, the CCD showed a dark count of about 5 count/pixel/sec and a read-out bias of about 350 count/pixel. Integration times with the $\mathrm{OH}$ and other narrow band filters were 9-20 seconds and 90-150 seconds, respectively. Average brightness of $\mathrm{OH}$ images was more than 10,000 count/bin, and thus its variation of $1 \%$ can be recognized with statistical significance. During the moonless hours of night, images were obtained sequentially at each filter approximately every 6 minutes. A standard procedure of analyzing observed allsky CCD images has been established in Chung (2005), which includes star removal, unwarping the hemispheric image into a flat airglow plane, and comparing subsequent images.

\section{STATISTICAL ANALYSIS OF BAND-TYPE WAVES}

Both band-type and ripple-type waves were detected in the OH Meinel band and OI 557.7 images, and their characteristics in the pilot phase of observation (July 2001 through March 2002) were reported by Chung et al. (2003). As other studies noted, observed parameters of the band-type waves, such as wavelengths and periods, are consistent with those of propagating gravity waves over a significant length of path, unlike the ripple-type waves, which are usually regarded as very local phenomena (Taylor \& Hapgood 1990). In this study we concentrate on statistically analyzing band-type waves, which might reflect regional characteristics more efficiently than the ripple-type waves. The horizontal scale of the region that band-type waves can represent can be considered to be about 10 times the horizontal wavelength of band-type waves, which is several hundred km. Furthermore, the band-type waves are most clearly discerned from background noises in the observed images, allowing us to carry out confident statistical analysis. The band-type waves are recognized with two selection criteria: (1) variation of two or more repetitive wave crests is more than $8 \%$ of the background brightness in the unwarped all-sky images; (2) the wave crests span more than $50 \%$ of a FOV within $50^{\circ}$ from the zenith in all-sky images. Fig. 1 shows examples of wave crests satisfying the criteria. These criteria led to a somewhat conservative detection of band-type waves compared to other studies using all-sky images (for example, Ejiri et al. 2001). In order to estimate how often the waves occurred during the observation period, we count clear moonless night time when two criteria are met: (1) cloud coverage was less than $30 \%$ of the FOV 


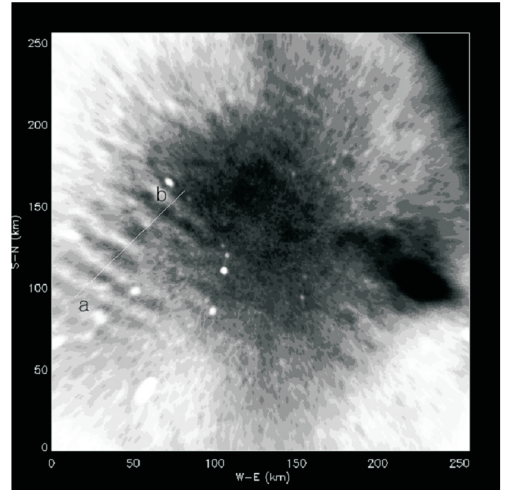

(a)

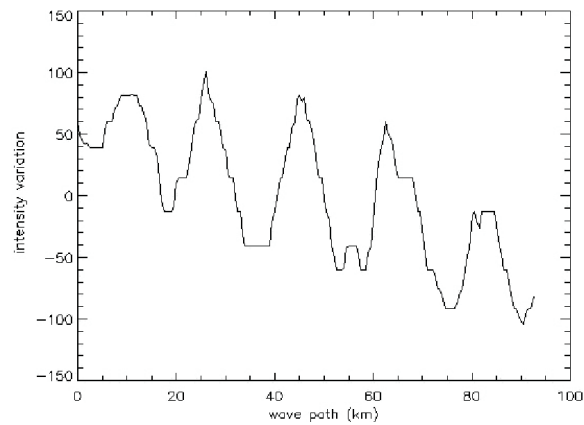

(c)

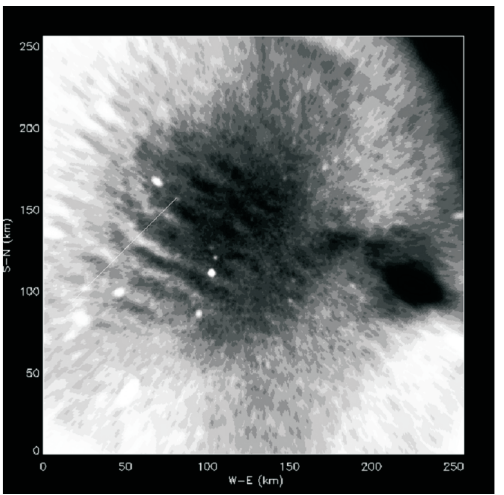

(b)

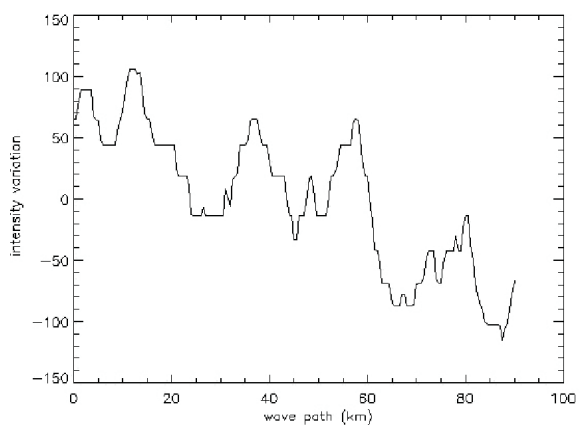

(d)

Fig. 1. Unwarped images taken at 01:26:39 and 01:35:55 January 7, 2005. The second rows are brightness profiles along the line (marked) in the unwarped images.

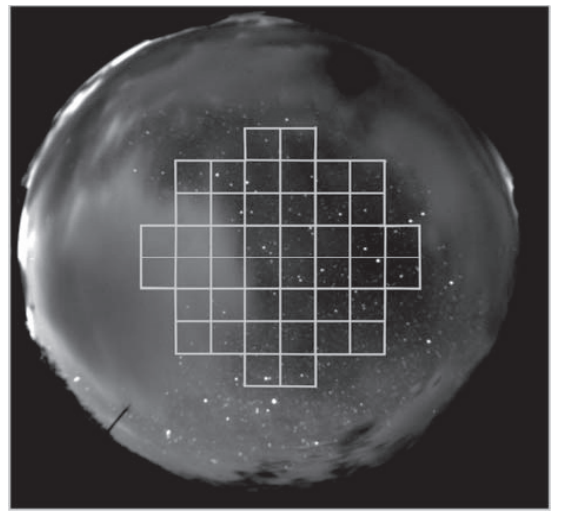

Fig. 2. An all-sky image with no filter. The central area within $50^{\circ}$ from the zenith is divided with 44 grids to determine cloud coverage.

within $50^{\circ}$ from the zenith in all-sky images with no filter, and (2) apparent moonlight effect should be limited within $40^{\circ}$ from the horizon. Fig. 2 shows an all-sky image with no filter that is overlapped with 44 grids to determine cloud coverage of the central part. These criteria should provide observation conditions that allow unambiguous wave detection in the all-sky images.

The total selected observing times for clear moonless nights were 12,417 minutes, 10,023 minutes and 1,077 minutes for $\mathrm{OI}, \mathrm{O}_{2}$, and $\mathrm{OH}$ filters, respectively. The total observed times with the $\mathrm{OH}$ filter were much shorter than those with other filters because $\mathrm{OH}$ images were taken with shorter exposure times in the observing cycles. During these selected observing times, the band-type waves were detected for a total of 3,068 minutes, 1,600 minutes, and 137 minutes for $\mathrm{OI}, \mathrm{O}_{2}$, and $\mathrm{OH}$ filters, respectively, which occurred a total of 67 nights during our observation period of 2001-2005. The wave occurrence percentages were 25,16 , and $13 \%$ for $\mathrm{OI}, \mathrm{O}_{2}$, and $\mathrm{OH}$ filters, respectively. These occurrence percentages are relatively lower than other all-sky observations, probably because our selection criteria for the band-type waves are significantly stronger than other studies (Taylor et al. 1998, Smith et al. 2000). Note that our occurrence percentages were determined by comparing actual time spans of wave appearance with clear moonless observing times, not just by counting nights of wave occurrences.

Histograms of the selected observing times are shown by the month for each filter in Fig. 3a. Observations were rarely carried out during June and July due to rainy weather. With these monthly clear moonless observing times, we compute the occurrence percentages of band-type waves, as shown in Fig. 3b. There seem to be 
two maxima in the occurrence percentages of waves in winter and summer. For the $\mathrm{OI}$ and $\mathrm{O}_{2}$ airglow waves, the monthly occurrences have a similar pattern. For the $\mathrm{OH}$ waves, the occurrence variation shows a somewhat different pattern, but the difference may not be statistically significant because of the brief observing time. The winter maximum is stronger than the summer maximum, which is not fully covered due to the rainy season. Similar variations in wave activities were reported with observations by SATIs at Shigaraki in Japan (Gavrilov et al. 2002) and at El Leoncito in Argentina (Reisin \& Scheer 2004). In Hawaii, Gavrilov et al. (2003) used MF radar observations to find the maximum wave intensity at the solstices below $83 \mathrm{~km}$, but at higher altitudes the times of maxima shift to the equinoxes.

The occurrences of OI and $\mathrm{O}_{2}$ airglow waves show a

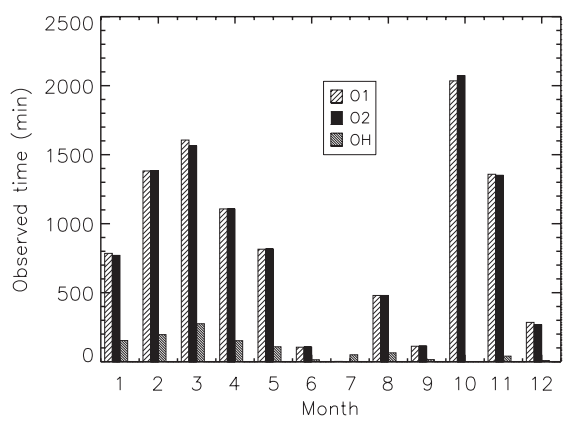

(a)

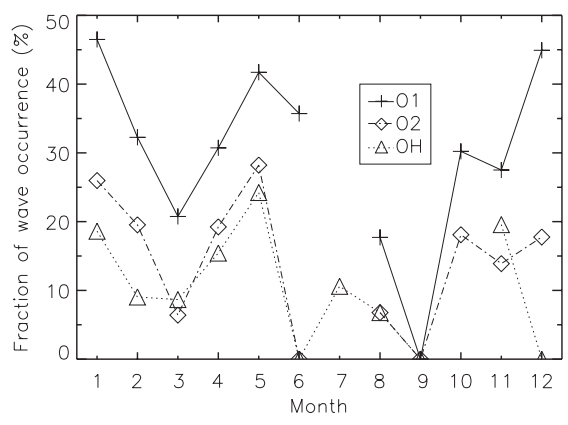

(b)

Fig. 3. a) Observed clear moonless times with $\mathrm{Ol}, \mathrm{O}_{2}$, and $\mathrm{OH}$ filters. Note that rainy season in June and July hampers all-sky observation. b) Monthly percentages of wave occurrences with $\mathrm{Ol}, \mathrm{O}_{2}$, and $\mathrm{OH}$ filters. Note that two minima appear in March and September.

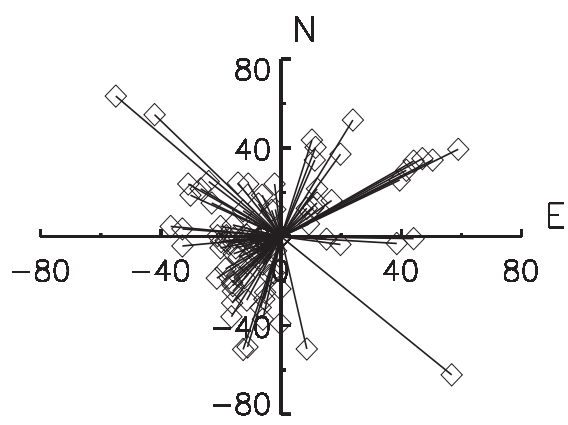

(a)

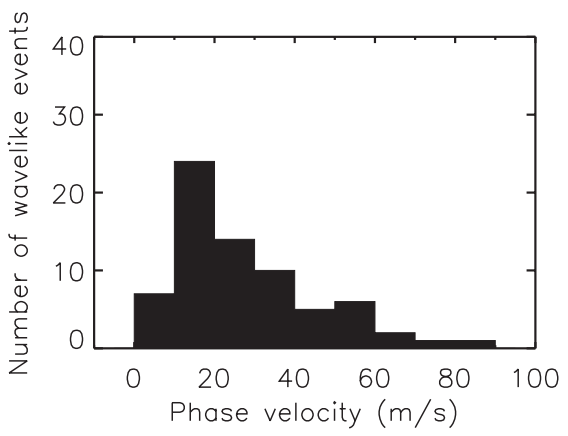

(c)

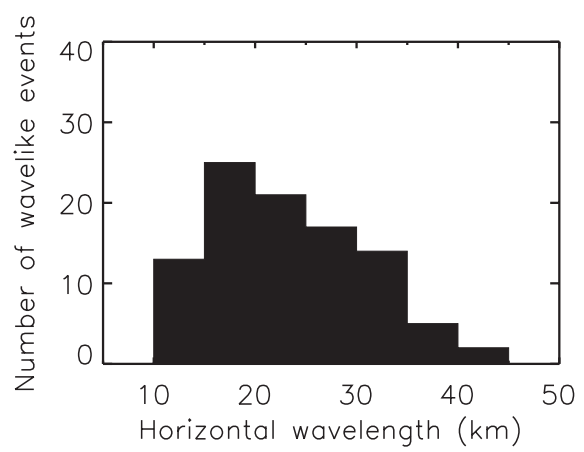

(b)

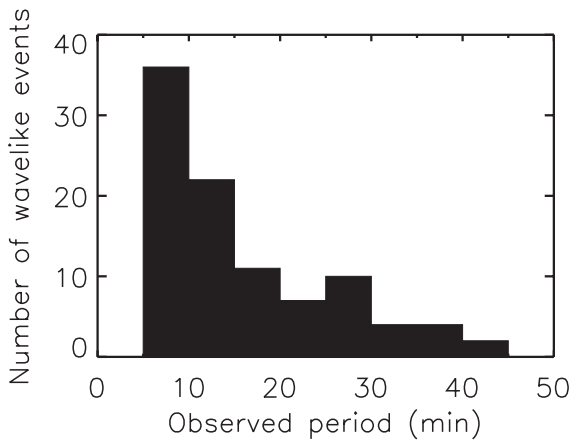

(d)

Fig. 4. Characteristics for band type waves measured at Mt. Bohyun during 67 nights from July 2001 through September 2005. (a) Velocity vectors were drawn as lines extending from the origin to the solid circle. (b)-(d) Histograms of band type waves for the horizontal wavelength $(\mathrm{km})$, phase speed $(\mathrm{m} / \mathrm{s})$, and apparent period $(\mathrm{min})$. 
clear minimum in March and a less confident minimum in September. However, Yang et al. (2006) reported equinox maxima in wave activities determined from $\mathrm{Na}$ lidar observations in Brazil. There seems to be a discrepancy between the wave activities determined from airglow observations and radar measurements. A total of 97 events of band-type waves are detected during the four-year period of observation. Wavelengths, phase speeds and periods of band-type waves are measured from the unwarped images that are converted from the all-sky images with adopted altitudes of 96, 95, and $87 \mathrm{~km}$ for OI, $\mathrm{O}_{2}$, and $\mathrm{OH}$ airglow layers (for OI557.7 Taylor et al. [1995], for $\mathrm{O}_{2}$ Cho [2006], for OH Baker \& Stair [1988]). The propagation directions and speeds of the detected waves are plotted in Fig. 4a, and histograms of their wavelengths, phase speeds, and periods are given in Figs. 4b-d, respectively. The mean horizontal wavelength $\left(\lambda_{h}\right)$ is $23 \pm 7 \mathrm{~km}$, the mean phase speed $\left(v_{o b}\right)$ is $32 \pm 18 \mathrm{~m} / \mathrm{s}$, and the mean apparent period $\left(\tau_{o b}\right)$ is $16 \pm 10 \mathrm{~min}$. The parameters of the band-type waves are consistent with short period internal gravity waves, as other previous studies have indicated (Taylor et al. 1993, Smith et al. 2000).

Phase velocity vectors of the waves are shown in Fig. 5 for four seasons. During fall and winter, the waves propa- gate westward almost exclusively, which may be due to the filtering of eastward waves by prevailing winds in the intermediate atmosphere. The waves during spring seem to travel more along the northeastward and southward, close to the meridional direction, than other directions. The four events of the waves during summer all move eastward, but are not sufficient to draw a statistical tendency.

\section{SEARCHING FOR WAVE SOURCES}

Using the observed wave parameters, namely horizontal wavelengths, propagation directions, and periods, we attempt to trace back the waves with a ray tracing program. The ray tracing for all 97 wave events is carried out with background wind and temperature profiles from the European Centre for Medium-Range Weather Forecasts $(E C M W F)^{1}$ at the observed times for altitudes lower than $40 \mathrm{~km}$, and with Cooperative Institute for Research in the Atmosphere (CIRA) ${ }^{2}$ plus tide data for altitudes between

'Source: http://www.ecmwf.int

${ }^{2}$ Source: http://www.cira.colostate.edu

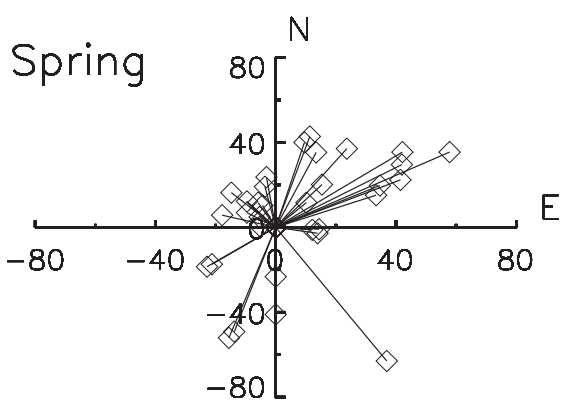

(a)

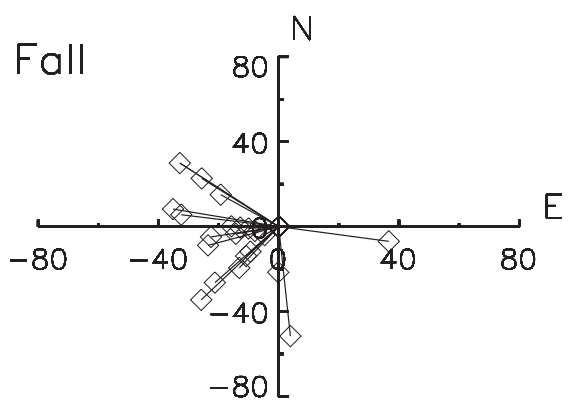

(c)

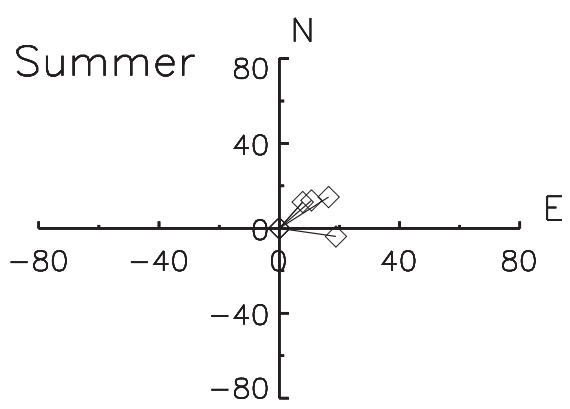

(b)

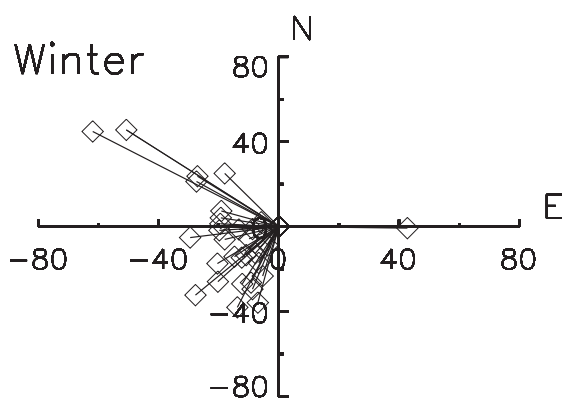

(d)

Fig 5. Seasonal trend of propagation directions and speeds of band type waves at Mt. Bohyun, Korea. Velocity vectors were drawn as lines extending from the origin to the solid circle. a) Spring (March-May), b) summer (June-August), c) fall (September-November), d) winter (December-February). 
Table 1. Ray tracing results of observed band-type waves.

\begin{tabular}{lcccccc}
\hline $\begin{array}{l}\text { Termination } \\
\text { altitude }(\mathrm{km})\end{array}$ & $0-20$ & $20-60$ & $>60$ & Untraceable & Undetermined & Total \\
\hline $\begin{array}{l}\text { Number of } \\
\text { events }\end{array}$ & 20 & 3 & 43 & 21 & 10 & 97 \\
\hline
\end{tabular}

40 and $120 \mathrm{~km}$ (Flemming et al. 1990, Swinbank \& O'Neill 1994, Hagan \& Forbes 2002). Table 1 shows ray tracing results in terms of termination altitudes to which the waves can be traced back from the airglow layers. Only 20 of the observed wave events can be traced back to tropospheric altitudes, while for 64 of the observed events the ray tracing computation was terminated at the mesospheric altitudes above $60 \mathrm{~km}$, including 21 events that cannot be traced back from the airglow altitude at all due to unfavorable atmospheric conditions. For 10 events, termination altitudes could not be determined because the uncertainties in the observed wave parameters were too large. For 3 events, the termination altitudes are in the range of $20-60 \mathrm{~km}$. Disregarding the 10 undetermined cases, only $23 \%$ of observed waves seemed to originate from tropospheric sources, whereas a clear majority, $74 \%$, were from mesospheric sources. In particular, the 21 untraceable events (24\%) may imply ducted waves that were trapped near the airglow layers, disenabling ray tracing computation.

The computed individual ray paths may not reflect actual paths because wind and temperature profiles used in the calculation above $40 \mathrm{~km}$ are only climatological values, which may differ from actual conditions at the time of wave observation. However, the overall results of ray tracing may have statistical significance in suggesting that the majority of the observed band-type waves may originate from mesospheric altitudes, not directly from tropospheric sources. Wrasse et al. (2006) reported similar results from their ray tracing study on all-sky images obtained in Brazil. The results also seem to suggest that the majority of the sources are horizontally not far from the observation site (68 events within $100 \mathrm{~km}$ ).

If the band-type waves indeed originate from the mesosphere, not directly from the troposphere, the observed waves may be secondary waves generated from the breaking of primary waves that already experience the filtering effect below mesospheric altitudes, in order to be consistent with the observed preferential direction of propagation. In addition, the secondary waves generated in the mesosphere near $60 \mathrm{~km}$ may experience a further filtering effect when they propagate upward to the airglow heights. Recent numerical simulations by Chun \& Kim (2007) show that a large portion of the upwardpropagating secondary waves is significantly filtered out above the mesospheric forcing when a strong background wind shear exists.

\section{DISCUSSION}

During the actual 32 observing months of 2001-2005, a total of 97 events of band-type waves were recorded by our all-sky airglow camera. The total time of the waves was about 80 hours, which are scattered across 67 nights and comprise $13-25 \%$ of clear moonless night times, depending on the airglow filters used. Smith et al. (2000) reported mesospheric wave activity on $55 \%$ of 21 nights from their all-sky imaging observation at Millstone Hill. Wu \& Killeen (1996) reported mesospheric gravity waves on $70 \%$ of the clear nights during summer months, but for less than $10 \%$ during other seasons at Peach Mountain. Taylor et al. (1998) detected gravity waves on 5 nights out of a two-week campaign observation during August at Yamagawa, Japan. Our occurrence percentages of the waves seem to be lower than those of other studies, but the occurrence percentages are strongly dependent on both the criteria for the wave detection and definition of clear night time, both of which are strict in our study. Our occurrence percentages are determined by adding up both lasting times of the wave events and clear moonless nighttimes minute by minute, not just night by night as in some other studies. Our strict method must have resulted in the low wave occurrence percentage, and can thus be considered as a lower limit for the occurrence percentage of the band-type waves in the airglow layers.

Despite the strict selection criteria for the band-type waves and the different method of wave analysis used, our estimation of wave occurrence shows a semi-annual variation (winter and summer maxima) similar to those determined from spectral observations of airglow layers by Gavrilov et al. (2002) in Japan, and by Reisin \& Scheer (2004) in Argentina. Our study relies on wave analysis of 2-dimensional data from an imaging camera, which is quite different from the analysis of 1-dimensional time series data from spectrometers. Semi-annual behavior of wave activity has been known from radar and lidar wind observations (references in Fritts \& Alexander 2003). However, some radar and lidar observations suggest that the semi-annual variation disappears or changes its phase above certain altitudes. From their lidar observation at Urbana $\left(40^{\circ} \mathrm{N}\right)$, Thornsen \& Franke (1998) reported that the semi-annual variation nearly disappears above $90 \mathrm{~km}$. In Hawaii, Gavrilov et al. (2003) found from MF radar observations that the times of maximum wave 
intensities shift from the solstices to the equinoxes above $\sim 83 \mathrm{~km}$. Yang et al. (2006) reported equinox maxima in wave activities determined from Na lidar observations in Brazil. Clemesha et al. (2006) suggested that the equinox maxima reported by Yang et al. (2006) may be related to wind shears in the mesosphere caused by tides, which are stronger near the equinox than the solstices at low latitudes. The radar and lidar may be observing different types of waves from those detected by the airglow observations. Waves detected by airglow observations may be biased toward larger vertical wavelengths, because waves with small vertical wavelengths may not make an observable modulation in the airglow layer. The mean vertical wavelengths of the observed waves is estimated to be 9.5 $\mathrm{km}$ from an approximate relation between horizontal $\left(\lambda_{h}\right)$ and vertical wavelengths $\left(\lambda_{z}\right)$, and observed period $\left(\tau_{o b s}\right)$, $\lambda_{z} \approx \lambda_{h}\left(\tau_{g} / \tau_{o b s}\right)$, where $\tau_{g}$, given a nominal value of $5 \mathrm{~min}$., is the inverse of the buoyancy frequency (Heins 1960).

Over our site, the observed waves tended to propagate preferentially westward during fall and winter and eastward during summer. A marked preference for wave propagation towards the N-NE was also found in a campaign observation of Taylor et al. (1998) during August 1996 in Japan. Wu \& Killeen (1996) noted eastward propagation during summer in the mid-western region of North America. The preferential directions are consistent with the filtering theory, in which eastward and westward waves from low altitudes are filtered out by eastward and westward wind fields in intermediate altitudes during winter and summer, respectively. However, our ray tracing study suggests that the majority of the observed waves originate from mesospheric altitudes above $60 \mathrm{~km}$, where the filtering effect is generally not significant due to the decreasing wind profile. In other words, if the waves are indeed generated with random directions in the mesospheric altitudes, the observed preferential direction of waves cannot be explained by the filtering effect. The waves may be, however, produced with the preferential direction in the mesospheric altitudes, as a primary wave breaks into secondary waves with the same propagation direction. Using numerical simulations, Snively \& Pasko (2003) demonstrated that gravity waves generated from the troposphere break and produce short period secondary waves at mesopause altitudes. Their simulations show that secondary waves are generated with the same propagation direction as primary waves. Thus, it is expected that waves with preferential directions will survive through the wind fields below the mesosphere, and break into secondary waves at the mesospheric altitudes (above $60 \mathrm{~km}$ ), which are observed at the airglow layers.
Furthermore, the secondary waves in their simulation tend to be ducted, as they are reflected by the upper and lower boundaries of the lower thermospheric duct. In our ray tracing study, about $20 \%$ of the observed waves that are not traceable due to inappropriate atmospheric conditions may correspond to the ducted secondary waves. Thus, about $70 \%$ of the observed waves at the airglow layers over our site seem to be secondary waves, which cannot be directly traced back to tropospheric original sources. The secondary waves generally have higher frequency and shorter wavelengths than the original waves before break-up, and at certain conditions the frequency and wave numbers of the secondary waves are doubled (Holton \& Alexander 1999, Snively \& Pasko 2003). Zhou et al. (2002) reported that the characteristics of the secondary waves can be determined mainly by the mesospheric forcing due to the breaking of gravity waves. The predicted characteristics of secondary waves may provide a way to check whether the band-type waves observed at the airglow layers are indeed mostly secondary waves. If one can compare the wave spectra measured at $\sim 60 \mathrm{~km}$, perhaps by MF radar, with those at the airglow altitudes ( $\sim 90$ $\mathrm{km}$ ), using spectral instruments or airglow cameras, one may find that the characteristics of wave spectra change from those of primary to those of secondary waves as the altitude increases.

\section{CONCLUSIONS}

All-sky imaging of OH Meinel, OI $557.7 \mathrm{~nm}$ and $\mathrm{O}_{2}$ atmospheric band airglow layers was carried out from July of 2001 through September of 2005 at Mt. Bohyun, Korea. When analyzing the observed all-sky images, we applied strict criteria in both detecting band-type waves and in specifically defining clear night conditions. A total of 97 events of band-type waves are detected for 25, 16, and $13 \%$ of clear moonless night time for $\mathrm{OI}, \mathrm{O}_{2}, \mathrm{OH}$ filters, respectively. The wave occurrence is significantly lower than other all-sky observations, which is probably due to our strict selection criteria. The wave occurrence shows a roughly semi-annual variation with maxima near solstices and minima near equinoxes, which is consistent with other studies of airglow wave observations. However, the semi-annual variation with maxima near equinoxes was reported by studies with radar and lidar, which measure waves at specific altitudes rather than in airglow layers. The waves seen with airglow observations may have adequate vertical wavelengths to modulate the airglow layers, and thus they may be different samples of waves 
from those observed with radar and lidar. The observed waves tended to propagate westward during fall and winter, and eastward during spring and summer. These propagation directions are consistent with the notion that waves with other directions are filtered out by prevailing winds at intermediate altitudes as they propagate from the tropospheric altitudes. However, our ray tracing study shows that majority of the observed waves seem to originate from the mesospheric altitudes (above $60 \mathrm{~km}$ ). If the observed waves at the airglow layers are secondary waves generated from primary waves that break up at the mesospheric altitudes, then the preferential directions and the apparent source altitudes can be explained, since the primary waves are already selected by filtering processes below the mesospheric altitudes. A recent numerical study of Snively \& Pasko (2003) shows secondary wave generation at the mesosphere. In order to verify this notion, further observational studies are needed, such as a comparison of wave spectral characteristics at different mesospheric altitudes.

\section{ACKNOWLEDGEMENTS}

We thank the Korea Astronomy and Space Science Institute for allowing us to operate the all-sky camera at Mt. Bohyun. This study was financially supported by a research grant from Chungnam National University in 2008.

\section{REFERENCES}

Baker, D. J. \& Stair, A. T. Jr. 1988, PhyS, 37, 611, doi: 10.1088/0031$8949 / 37 / 4 / 021$

Cho, Y. 2006, PhD Thesis, York University

Chun, H. Y. \& Kim, Y. H. 2007, in International Symposium on Coupling Processes in the Equatorial Atmosphere (Kyoto, Japan), p.48

Chung, J. K. 2005, PhD Thesis, Chungnam National University

Chung, J. K., Kim, Y. H., \&Won, Y. I. 2003, AdSpR, 32, 825, doi: 10.1016/S0273-1177(03)00414-9

Clemesha, B., Yang, G., Tokumoto, A., Bastista, P., \& Simonich, D. 2006, in 36th COSPAR Scientific Conference (Beijing, China: Committee on Space Research), p.172

Ejiri, M. K., Shiokawa, K., Ogawa, T., Igarashi, K., Nakamura, T., Maekawa, R., Tsuda, T., \& Kubota, M. 2001, JGRD, 106 , 22793, doi: 10.1029/2001JD900225

Flemming, E. L., Chandra, S., Barnett, J. J., \& Corney, M.
1990, AdSpR, 10, 11

Fritts, D. C. \& Alexander, M. J. 2003, RvGeo, 41, 1003, doi: 10.1029/2001RG000106

Garcia, F. L. 1999, PhD Thesis, Cornell University

Gavrilov, N. M., Riggins, D. M., \& Fritts, D. C. 2003, JGR, 108, 4655, doi: 10.1029/2002JD003131

Gavrilov, N. M., Shiokawa, K., \& Ogawa, T. 2002, JGR, 107, 4755, doi: 10.1029/2001JD001469

Hagan, M. E. \& Forbes, J. M. 2002, JGR, 107, 4754, doi: 10.1029/2001JD001236

Hecht, J. H., Walterscheid, R. L., \& Ross, M. N. 1994, JGRA, 99, 11449, doi: 10.1029/94JA00584

Heins, C. O. 1960, CaJPh, 38, 1441

Holton, J. R. \& Alexander, M. J. 1999, TellB, 51, 45, doi: 10.1034/j.1600-0889.1999.00005.x

Isler, J. R., Taylor, M. J., \& Fritts, D. C. 1997, JGRD, 102, 26301, doi: 10.1029/97JD01783

Lindzen, R. S. 1981, JGRC, 86, 9707, doi: 10.1029/JC086iC10p 09707

Reisin, E. R. \& Scheer, J. 2004, JASTP, 66, 655, doi: 10.1016/j. jastp.2004.01.017

Smith, S. M., Mendillo, M., Baumgardner, J., \& Clark, R. R. 2000, JGRA, 105, 27119, doi: 10.1029/1999JA000343

Snively, J. B. \& Pasko, V. P. 2003, GeoRL, 30, 2254, doi: 10.1029/2003GL018436

Swinbank, R. \& O'Neill, A. 1994, GeoRL, 21, 2099, doi: 10.1029/94GL01743

Taylor, M. J., Fritts, D. C., \& Isler, J. R. 1995, GeoRL, 22, 2837, doi: 10.1029/95GL02945

Taylor, M. J. \& Hapgood, M. A. 1990, P\&SS, 38, 1421, doi: 10.1016/0032-0633(90)90117-9

Taylor, M. J., Hapgood, M. A., \& Rothwell, P. 1987, P\&SS, 35, 413, doi: 10.1016/0032-0633(87)90098-5

Taylor, M. J., Ryan, E. H., Tuan, T. F., \& Edwards, R. 1993, JGR, 98, 6047, doi: 10.1029/92JA02604

Taylor, M. J., Seo, S. H., Nakamura, T., Tsuda, T., Fukunish, H., \& Takahashi, Y. 1998, GeoRL, 25, 1797, doi: 10.1029/98GL00847

Thornsen, D. \& Franke, S. J. 1998, JGR, 103, 3767, doi: 10.1029/97JD03548

Wrasse, C. M., Nakamura, T., Tsuda, T., Takahashi, H., Medeiros, A. F., Taylor, M. J., Gobbi, D., Salatun, A., Suratno, Achmad, E., \& Admiranto, A. G. 2006, JASTP, 68, 163, doi: 10.1016/j.jastp.2005.10.012

Wu, Q. \& Killeen, T. L. 1996, GeoRL, 23, 2211, doi: 10.1029/96GL 02168

Yang, G., Clemesha, B., Batista, P., \& Simonich, D. 2006, JGRD, 111, 211107, doi: 10.1029/2005JD006900

Zhou, X., Holton, J. R., \& Mullendore, G. L. 2002, JGRD, 107, 4058, doi: 10.1029/2001JD001204 